\title{
Exploring the Electrophysiologic and Hemodynamic Effects of Cardiac Resynchronization Therapy
}

Citation for published version (APA):

Schreurs, R., Wiegerinck, R. F., \& Prinzen, F. W. (2017). Exploring the Electrophysiologic and Hemodynamic Effects of Cardiac Resynchronization Therapy: From Bench to Bedside and Vice Versa. Heart Failure Clinics, 13(1), 43-52. https://doi.org/10.1016/j.hfc.2016.07.004

Document status and date:

Published: 01/01/2017

DOI:

10.1016/j.hfc.2016.07.004

Document Version:

Publisher's PDF, also known as Version of record

Document license:

Taverne

\section{Please check the document version of this publication:}

- A submitted manuscript is the version of the article upon submission and before peer-review. There can be important differences between the submitted version and the official published version of record.

People interested in the research are advised to contact the author for the final version of the publication, or visit the DOI to the publisher's website.

- The final author version and the galley proof are versions of the publication after peer review.

- The final published version features the final layout of the paper including the volume, issue and page numbers.

Link to publication

\footnotetext{
General rights rights.

- You may freely distribute the URL identifying the publication in the public portal. please follow below link for the End User Agreement:

www.umlib.nl/taverne-license

Take down policy

If you believe that this document breaches copyright please contact us at:

repository@maastrichtuniversity.nl

providing details and we will investigate your claim.
}

Copyright and moral rights for the publications made accessible in the public portal are retained by the authors and/or other copyright owners and it is a condition of accessing publications that users recognise and abide by the legal requirements associated with these

- Users may download and print one copy of any publication from the public portal for the purpose of private study or research.

- You may not further distribute the material or use it for any profit-making activity or commercial gain

If the publication is distributed under the terms of Article $25 \mathrm{fa}$ of the Dutch Copyright Act, indicated by the "Taverne" license above, 


\title{
From Bench to Bedside and Vice Versa
}

\author{
Rick Schreurs, MD, Rob F. Wiegerinck, PhD,
} Frits W. Prinzen, PhD*

\section{KEYWORDS}

- Left bundle branch block $\bullet$ Cardiac resynchronization therapy $\bullet$ Animal research

- Electrophysiology $\bullet$ Hemodynamics

\section{KEY POINTS}

- CRT reduces the dyssynchronous activation pattern caused by LBBB and improves the hemodynamic state. This results in reduced mortality and improved quality of life.

- For the best CRT response the LV lead should be positioned in a late activated area while avoiding sites with transmural myocardial infarction.

- The addition of more pacing sites further improves the hemodynamic state, but only if the first LV pacing site yielded a low hemodynamic response.

- An endocardial LV pacing site is superior to an epicardial LV pacing site with respect to CRT response.

- $\mathrm{AV}$ and $\mathrm{VV}$ optimization further increase the response to $\mathrm{CRT}$ by fusing intrinsic and paced electrical activation fronts.

\section{INTRODUCTION}

Patients with heart failure (HF) combined with left bundle branch block (LBBB) have broad QRS complexes and an impaired cardiac function. In these patients it is unclear whether HF leads to LBBB or vice versa. Animal models, however, have shown that induction of LBBB reduces cardiac contractility. ${ }^{1}$ Similarly, inadvertent induction of LBBB during transcatheter aortic valve replacement worsens outcome. ${ }^{2}$ In LBBB cardiac function is impaired because the left (LV) and right ventricle (RV) and various regions within the LV are not activated simultaneously, leading to dyssynchronous

This article originally appeared in Cardiac Electrophysiology Clinics, Volume 7, Issue 4, December 2015.

Disclosure Statement: F.W. Prinzen received research grants from Medtronic, Boston Scientific, EBR Systems, St. Jude Medical, Biological Delivery System (Johnson and Johnson), MSD, and Proteus Medical. This research was performed within the framework of CTMM (Center for Translational Molecular Medicine), the Center for Translational Molecular Medicine (www.ctmm.nl), project COHFAR (COngestive Heart Failure and ARrhythmia; grant 01C-203), and supported by the Dutch Heart Foundation.

Department of Physiology, Cardiovascular Research Institute Maastricht, Maastricht University, Maastricht, The Netherlands

* Corresponding author. Department of Physiology, Maastricht University, PO Box 616, Maastricht 6200 MD, The Netherlands.

E-mail address: frits.prinzen@maastrichtuniversity.nl 
contraction and reduced cardiac pump function. ${ }^{3}$ Animal studies have shown that isolated LBBB causes reduction in ejection time, slower rates of rise and fall of the LV pressure, and prolonged duration of isovolumic contraction and relaxation. ${ }^{4}$

Cardiac resynchronization therapy (CRT) aims to restore synchronous contraction of the heart by either LV free wall or biventricular (BiV) pacing. The first studies started during the late 1990s to evaluate the effect of CRT. ${ }^{5-7}$ According to the current guidelines a CRT device is indicated for patients with HF and prolonged QRS duration, preferably with LBBB morphology on the electrocardiogram (ECG). ${ }^{8}$ CRT reduces mortality and improves quality of life, ${ }^{9}$ but additional research is needed to optimize this therapy. To this purpose investigations have also been performed in animal models of dyssynchrony.

Animals have long been used to study hemodynamics and electrophysiology in HF. As reviewed by Strik and colleagues ${ }^{10}$ the canine seems to be the best species to study ventricular conduction abnormalities that occur during pacing and LBBB, because the anatomic structures of the bundle branches are comparable with those in human. Percutaneous radiofrequency ablation of the LBBB results in a model perfectly suited to study the effects of CRT. ${ }^{1,4,11,12}$ This model enables the investigation of the role of LBBB and $\mathrm{CRT}$ in the absence of $\mathrm{HF}$, but if needed, also in combination with HF (created by chronic tachypacing) or myocardial infarction. ${ }^{10}$

This article reviews the electrophysiologic and hemodynamic effects of CRT in animal models and patients with LBBB.

\section{ELECTROMECHANICS OF DYSSYNCHRONY}

In LBBB the normal activation pattern is disturbed because the LV is no longer activated via the left bundle branch and Purkinje fibers. Instead, the electrical activation spreads from the normally activated RV through the septum toward the LV. Because activation moving from myocyte to myocyte is much slower, the LV free wall, which is the site most remote from the RV, is activated latest. Several clinical ${ }^{13,14}$ and preclinical ${ }^{15}$ invasive electrocardiac mapping studies have shown that the activation in LBBB hearts follows a specific pattern. LV depolarization moves from the septum in a circumferential and longitudinal direction. However, because conduction often appears slow at the RV-LV junctions an important contribution of activation comes from the wavefront passing over the apex toward the LV lateral wall (referred to as U-shaped activation pattern). Another characteristic feature is the slow transseptal conduction in LBBB, possibly caused by the vertical orientation of the laminar sheets of myocytes in the septum. ${ }^{16,17}$ Epicardial activation maps generated with noninvasive electrocardiographic imaging show comparable electrical patterns, as illustrated by the white arrow in the upper left of Fig. 1. ${ }^{18}$ The prolonged activation of the LV results in an increased total activation time (TAT) of both ventricles, which is characterized by a widened QRS complex on the surface ECG. ${ }^{13}$ These findings are similar in dogs. ${ }^{10}$

Fig. 2 (left) describes how the dyssynchronous electrical activation of the LV causes the early activated septum to contract against a reduced load, which leads to prestretch of the LV lateral wall (ie, more positive strain; middle, solid line)..$^{13}$ This prestretch increases contractile force of the LV free wall, which on its turn paradoxically stretches the septum later in systole (positive strain of the septum, dashed line). Both types of systolic stretching can be considered wasted work, which is the ratio of negative and positive work (red and black lines, respectively; bottom). ${ }^{3,19}$

In canine hearts, the maximum rates of rise and fall of the LV pressure ( $\mathrm{dP} / \mathrm{dt}_{\max }$ and $\left.\mathrm{dP} / \mathrm{dt}_{\min }\right)$ decrease immediately on creating LBBB and this decrease is still present after 8 weeks. Echocardiographic follow-up shows an increase of enddiastolic volume (EDV) and end-systolic volume (ESV) and decrease of ejection fraction (EF) with longer lasting LBBB. $^{3}$ These findings replicate the low EF, increased LV wall stress and ESV, and impaired myocardial relaxation as seen in patients with LBBB. ${ }^{20}$

\section{ELECTROPHYSIOLOGIC EFFECTS OF CARDIAC RESYNCHRONIZATION THERAPY}

The basic idea behind CRT is to resynchronize the late and more slowly activated LV by individually pacing both ventricles. Fig. 1 shows that RV pacing alone results in an activation pattern that resembles the intrinsic activation pattern of LBBB and leads to a QRS duration of 250 milliseconds (ms) in this example. At a short atrioventricular (AV) delay LV pacing increases QRS duration, but with a completely reversed activation pattern compared with LBBB and RV pacing. With BiV pacing the left and right activation wavefronts fuse in the LV, which accelerates its activation, and consequently result in a shorter QRS duration of $150 \mathrm{~ms}$.

In dogs simultaneous RV and LV pacing shortens TAT and QRS duration compared with the LBBB situation and immediately improves hemodynamics. ${ }^{10}$ However, note that BiV pacing does not necessarily reduce QRS duration ${ }^{6,7}$ or 

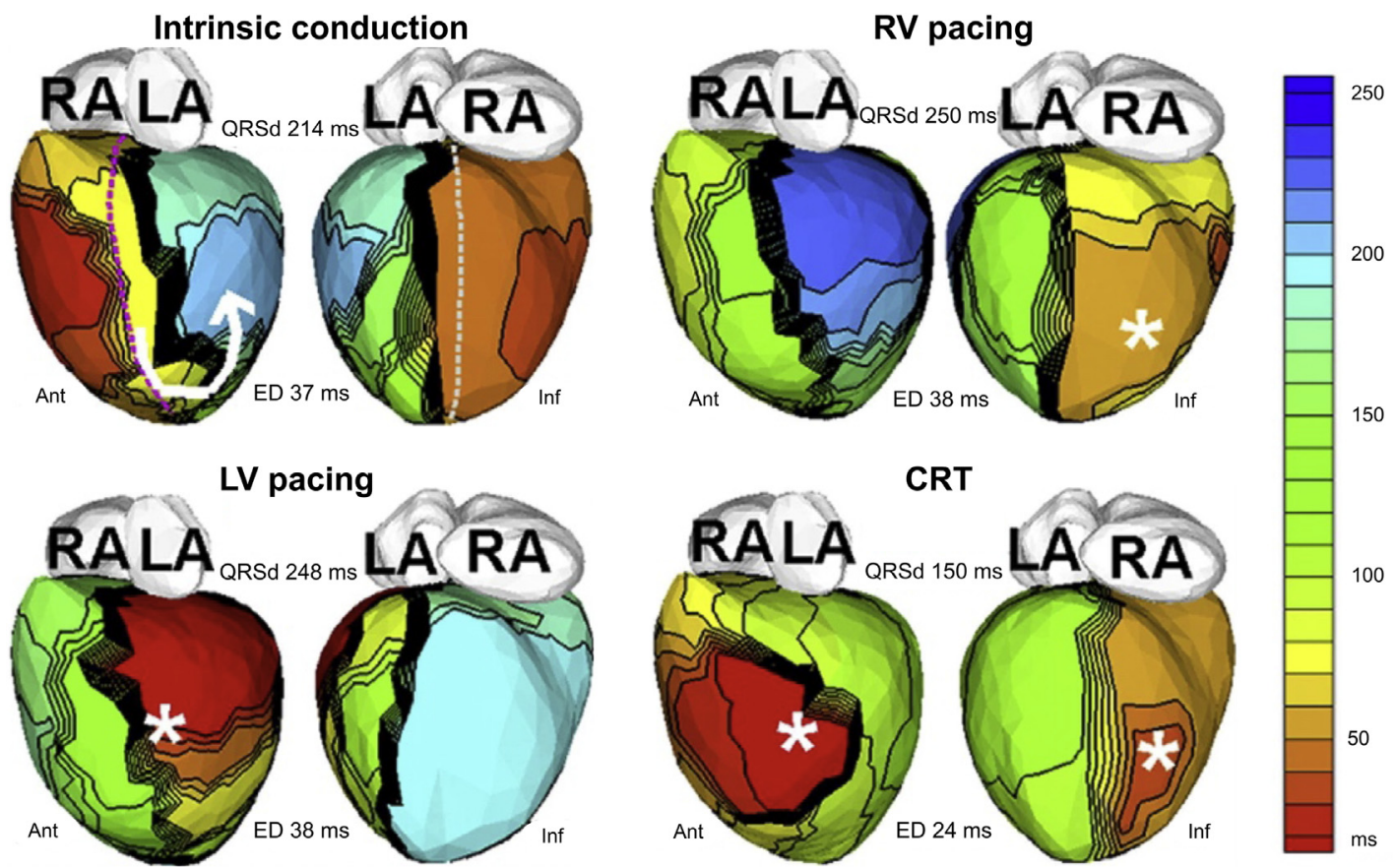

Fig. 1. Electrocardiographic images of an LBBB patient recorded during intrinsic conduction, RV pacing, LV pacing, and CRT. Each pair of images shows the anterior (Ant) and inferior (Inf) views. The black lines depict isochronal lines. Crowded isochronal lines indicate slow conduction. Thick black lines indicate conduction block. An asterisk indicates the pacing site. The dotted lines in the images of intrinsic conduction show the septal aspect of the epicardium. The QRS duration (QRSd) and the electrical dyssynchrony index (ED; calculated as the standard deviation of activation times at 500 sites in the LV) are indicated in the figure for each pacing modality. LA, left atrium; RA, right atrium. (From Ghosh S, Silva JN, Canham RM, et al. Electrophysiologic substrate and intraventricular left ventricular dyssynchrony in nonischemic heart failure patients undergoing cardiac resynchronization therapy. Heart Rhythm 2011;8(5):695; with permission.)

TAT, ${ }^{14}$ which can be explained by prolonged activation of the RV that is not intrinsically activated anymore (ie, slower cell-to-cell conduction instead of activation through the Purkinje network; compare intrinsic conduction and RV pacing in Fig. 1). Moreover, in dogs it has been shown that hemodynamic improvement can even occur when the QRS duration has not shortened because of CRT.

In responders CRT reduces LV dyssynchrony, measured as LV TAT or as the electrical dyssynchrony index (Fig. 1; lowest for BiV pacing). ${ }^{18}$ CRT reduces the difference in the onset of electrical activation between LV and RV. ${ }^{11}$ Ultimately, the intraventricular and interventricular (VV) resynchronization improve pump function.

\section{ACUTE HEMODYNAMIC EFFECTS OF CARDIAC RESYNCHRONIZATION THERAPY}

In dogs with LBBB acute BiV pacing raises dP/ $\mathrm{dt}_{\max }$ almost back to pre-LBBB levels, without affecting LV end-systolic or end-diastolic pressures. In canines with LBBB and tachypacing induced $\mathrm{HF}$ the relative increase in $\mathrm{LV} \mathrm{dP} / \mathrm{dt}_{\max }$ is larger than in nonfailing LBBB hearts, but the absolute increase is comparable. ${ }^{15}$ In patients the onset of BiV pacing immediately increases LV $\mathrm{dP} / \mathrm{dt}_{\max }$ compared with LBBB or RV pacing and this increase typically ranges from $10 \%$ to $30 \% .^{6,7,21}$

$\mathrm{LV} \mathrm{dP} / \mathrm{dt}_{\max }$ has become an important variable for hemodynamic studies in CRT, but also pulse pressure and cardiac index increase during BiV stimulation. ${ }^{6,21,22}$ Pressure-volume loop analysis in dogs with LBBB and HF shows an increase in stroke volume and stroke work (SW) in BiV pacing compared with baseline measurements. ${ }^{7}$ It has been suggested that $S W$ is a more reliable measure

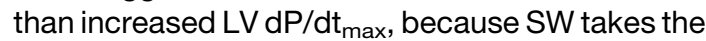
complete systolic phase into account and comprises pressure and volume changes, whereas LV $\mathrm{dP} / \mathrm{dt}_{\text {max }}$ only reflects the isovolumic contraction of cardiac systole. ${ }^{23}$ However, the acute improvement in LV $\mathrm{dP} / \mathrm{dt}_{\max }$ may not be able to predict the clinical outcome on the long-term. ${ }^{24}$ 
LBBB

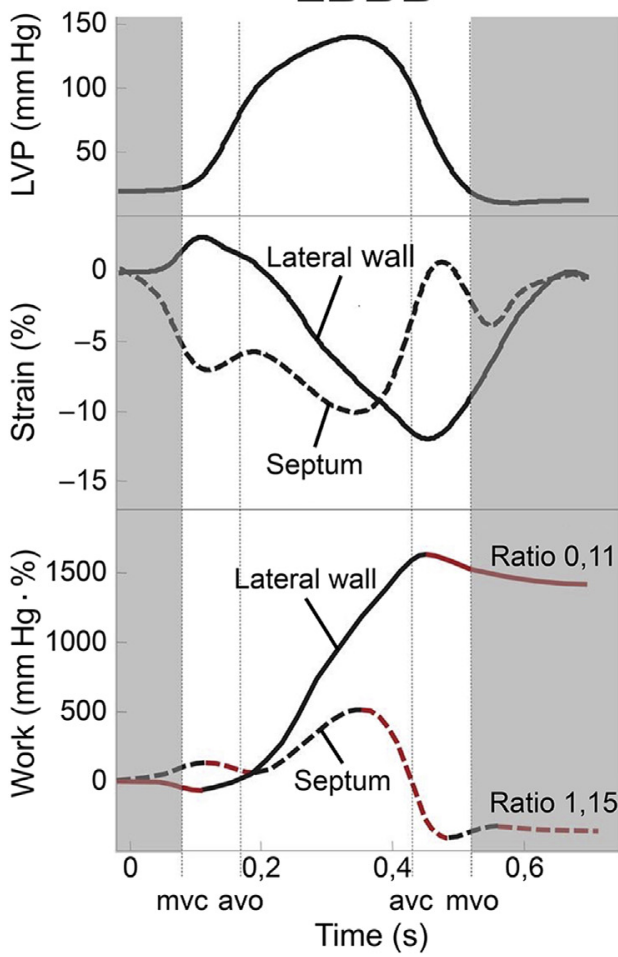

Acute CRT

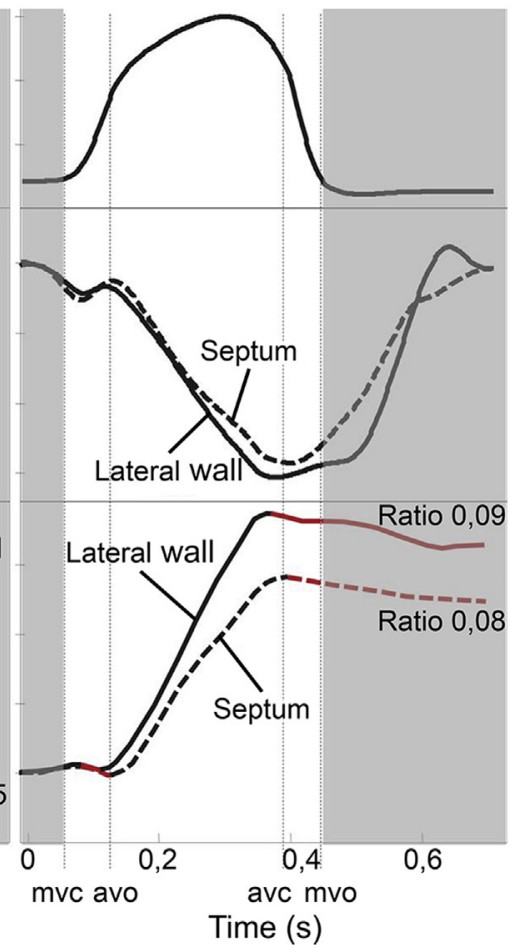

Fig. 2. Estimated LV pressure (top), strain (middle), and calculation of wasted work for the septum and lateral wall (bottom) in a representative patient with LBBB (left) and after treatment with CRT (right). Vertical lines indicate valvular events defined by echocardiography. Negative and positive work during systole is marked as red and black, respectively. Wasted work ratios were calculated using cumulated work between the closure and subsequent opening of the mitral valve (MVC and MVO, respectively). AVC, aortic valve closure; AVO, aortic valve opening. (From Russell K, Eriksen M, Aaberge L, et al. Assessment of wasted myocardial work: a novel method to quantify energy loss due to uncoordinated left ventricular contractions. Am J Physiol Heart Circ Physiol 2013;305(7):H998; with permission.)

\section{LONG-TERM EFFECTS OF CARDIAC RESYNCHRONIZATION THERAPY}

The favorable outcomes of CRT can be explained by reverse remodeling of the heart because of resynchronization of the ventricles. Remodeling can be activated through neurohormonal activation, differences in mechanical load, and wall stress. Several studies in animal models of LBBB, sometimes in combination with tachypacing-induced $\mathrm{HF}$, have shed led light on the cellular and molecular adaptations in asynchronous hearts. The expression of some genes and proteins is depressed uniformly, whereas others show regional differences in expression between early and late-activated areas. Changes occur related to myocyte function, calcium handling, $\beta$-adrenergic responsiveness, mitochondrial ATP synthase activity, cell survival signaling, and other functions. CRT reverses many of these alterations (discussed elsewhere in this issue).
These extensive reverse-remodelling processes may also explain the improvements in pressurevolume diagrams recorded after 6 months of CRT (Fig. 3). Note that after 6 months EDV and ESV show a leftward shift, whereas EF increases. ${ }^{25}$ Moreover, whereas before CRT the loops decrease in size with increased heart rate, this was much less the case after 6 months of CRT, indicating better pump function. Other studies report higher EF and lower end-systolic ventricular dimensions after 1 year of followup. ${ }^{23,26}$ A study in the LBBB canine model shows that acute CRT restores $\mathrm{dP} / \mathrm{dt}_{\text {max }}$ almost back to pre-LBBB values and chronic CRT increases it slightly further, yet not completely back to preLBBB values. ${ }^{12}$

\section{PACING LOCATION}

The size of hemodynamic response to CRT depends on the location of the LV lead. Usually the 


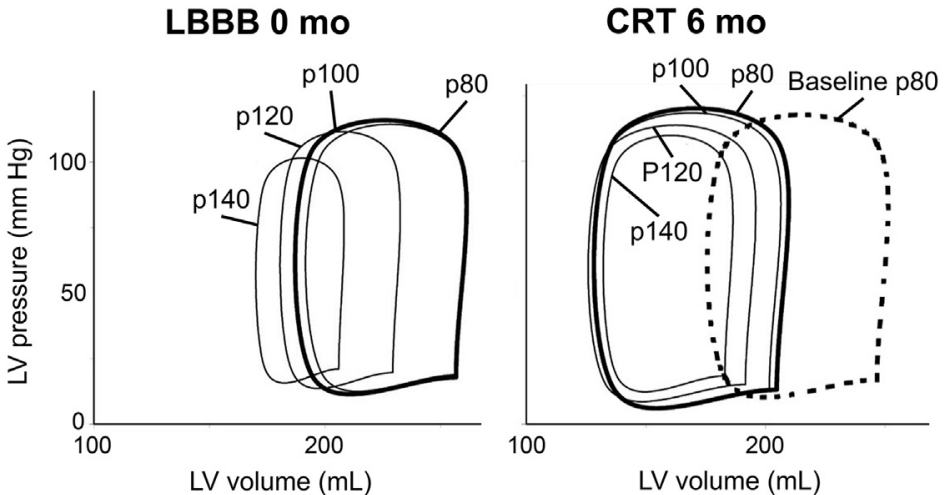

Fig. 3. Pressure-volume loops at baseline and after 6 months of CRT in a patient, measured at heart rates of $80,100,120$, and 140 beats per minute. (From Steendijk P, Tulner SA, Bax JJ, et al. Hemodynamic effects of long-term cardiac resynchronization therapy: analysis by pressure-volume loops. Circulation 2006;113(10):1301; with permission.) best location is in the latest activated region of the LV free wall. ${ }^{27}$ Intriguingly, most studies fail to indicate an anatomic location that is clearly the best. A study in LBBB dogs showed that pacing in a rather large area of the LV free wall $( \pm 43 \%)$ yielded a dP/ $\mathrm{dt}_{\max }$ larger than $70 \%$ of the maximal observed value. ${ }^{28}$ This, coupled with the fact that anatomy limits the number of available pacing sites, may explain the lack of a clear anatomic defined location for pacing. Moreover, LV activation patterns vary considerably between patients. Therefore, it seems advisable to estimate the ideal LV pacing region in each individual patient. ${ }^{27}$ To this purpose, the Cardiolnsight technique (see Fig. 1), other electroanatomic techniques, ${ }^{29}$ and echocardiographic speckle tracking ${ }^{30}$ may be used to determine the latest activated regions.

Currently, the site of latest activation is determined during intrinsic activation, but it is probably wiser to determine it during RV apex pacing because during CRT the RV is paced, which may shift the site of latest activation (see Fig. 1; compare intrinsic conduction and RV pacing). ${ }^{31,32}$

\section{MYOCARDIAL SCARRING}

Myocardial scarring plays a dual role in CRT response. First, the response to $C R T$ is inversely related to the total amount of ventricular scar tissue. ${ }^{33}$ Second, CRT response is poor, and potentially adverse if the LV lead is positioned in a region with extensive scar tissue. ${ }^{33,34}$ This may be because scar tissue slows electrical conduction and may give rise to ventricular arrhythmias. However, a study in canines indicates that CRT should still be considered for patients with a myocardial scar. ${ }^{35}$ In this study CRT reduces LV TAT and increases LV dP/dt $\max _{\text {ax }}$ to similar values in LBBB dogs with and without infarction when pacing sites are selected outside of the infarcted region (Fig. 4).

\section{MULTIPLE PACING SITES}

Because BiV pacing leads to electrical resynchronization of the LV, it has been argued that increasing the number of LV pacing sites (multiLV) will further improve resynchronization and cardiac function. The prospective TRIP-HF study shows that reverse remodelling is more pronounced after 3 months of triventricular pacing (two LV leads) compared with conventional BiV pacing, with higher EF and lower ESV in patients who did not respond to conventional BiV pacing. ${ }^{36}$ Experiments using a strategy to maximally resynchronize the LV in the canine LBBB model show that additional pacing sites (up to seven) consistently decrease LV TAT, but only increase $\mathrm{dP} / \mathrm{dt}_{\max }$ if the hemodynamic effect of pacing the initial single-site is small (Fig. 5A). ${ }^{37}$ Similar findings were reported later for CRT patients (Fig. 5B).

Although multisite pacing often requires leads in multiple veins, the recently introduced quadripolar leads enable multipoint pacing at two LV sites in one cardiac vein. The first studies on multipoint pacing have shown a small but significant increase in $\mathrm{dP} / \mathrm{dt}_{\max }$ and decrease in QRS duration compared with BiV pacing. ${ }^{38,39}$ Although these results are promising, all studies so far relate to individual optimization using invasive hemodynamic measurements and no long-term benefits and clinical implications have yet been reported.

\section{ENDOCARDIAL PACING}

Previous paragraphs mostly discussed (multiple) LV epicardial pacing sites, because the conventional lead position in the coronary vein is epicardial. However, both animal and patient studies indicate that LV endocardial pacing is more promising (see Fig. 5). ${ }^{39,40}$ Several other studies corroborated these findings. ${ }^{41,42}$ The better resynchronization with endocardial CRT is explained 


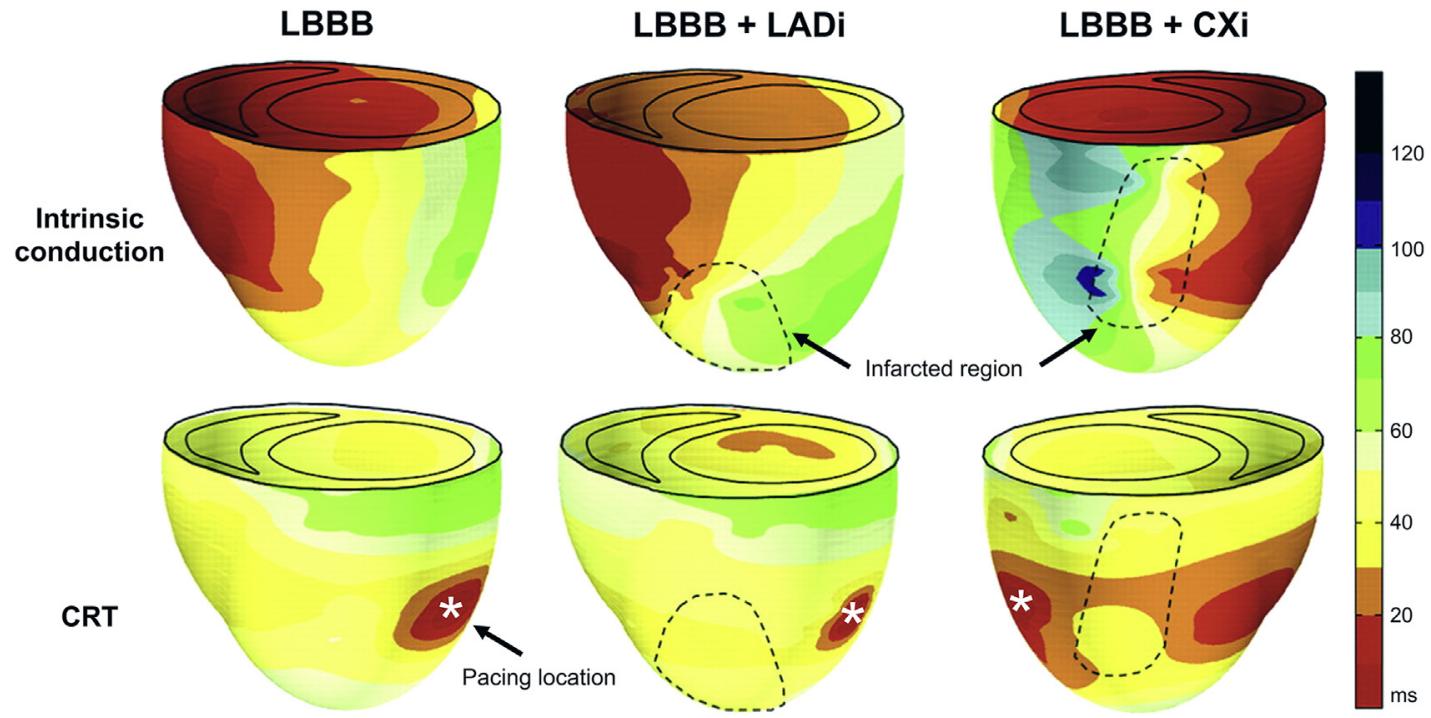

Fig. 4. Three-dimensional reconstruction of electrical activation times of the $L V$ and RV during intrinsic conduction (LBBB, top) and CRT using midlateral LV wall pacing (bottom) in representative hearts with LBBB (left), and LBBB combined with an infarction of the left anterior ascending artery (LBBB + LADi, middle) or left circumflex artery (LBBB + LCXi, right). (From Rademakers LM, van Kerckhoven R, van Deursen CJ, et al. Myocardial infarction does not preclude electrical and hemodynamic benefits of cardiac resynchronization therapy in dyssynchronous canine hearts. Circ Arrhythm Electrophysiol 2010;3(4):363; with permission.)

A



B



Fig. 5. Percentage change in LV dP/ $\mathrm{dt}_{\max }$ versus baseline during conventional (Conv) CRT (white bars), multisite or multipoint (gray bars), and endocardial pacing (black bars) measured in a canine LBBB model $(A)$ and in patients $(B)$. The values in the bars are presented as mean + SEM. The three lines in $A$ are the pooled data for the two "worst," the three "intermediate," and two "best" single LV pacing sites (red, black, and green, respectively). ${ }^{a} P \leq .05$ versus conventional CRT. (Adapted from Ploux S, Strik $M$, van Hunnik $A$, et al. Acute electrical and hemodynamic effects of multisite left ventricular pacing for cardiac resynchronization therapy in the dyssynchronous canine heart. Heart Rhythm 2014;11(1):123; and Shetty AK, Sohal M, Chen Z, et al. A comparison of left ventricular endocardial, multisite, and multipolar epicardial cardiac resynchronization: an acute haemodynamic and electroanatomical study. Europace $2014 ; 16(6): 875$.) 
by three factors: (1) a shorter path length for the depolarization wave to reach all regions of the ventricles, (2) more rapid impulse conduction in the endocardium than in the epicardium, and (3) a more rapid transmural conduction from endocardium to epicardium than in the opposite direction. ${ }^{40,43}$ Unfortunately, practical implementation of endocardial CRT is still problematic, because currently leads placed in the LV cavity require anticoagulation and also show significant dislodgement. $^{44}$

\section{OPTIMIZATION OF TIMING OF PACING}

All CRT devices have the option to adjust the AV and VV delay to the individual patient. Fig. 6A shows schematically how these different settings can influence the electrical activation of the LV. The $V V$ intervals (y-axis) can be chosen such that either the RV or the LV is activated first or that both are activated simultaneously. This determines the relative contribution to the complete electrical activation of the LV by activation fronts initiated by the LV pacing site and the RV pacing site and/ or intrinsic activation from the RBB. AV delays ( $x-$ axis) shorter, equal to, or longer than the intrinsic
AV delay influence the relative contribution of the intrinsic and paced activation wavefronts to the complete activation of the LV (see Fig. 6A). These settings affect pump function primarily by optimizing the degree of resynchronization. ${ }^{12,45}$ Fig. 6B shows the relative changes in $\mathrm{LV} \mathrm{dP/dt}$ max, $\mathrm{SW}$, and electrical resynchronization in response to 100 different combinations of LV (x-axis) and RV (y-axis) AV delays. Note the similar leftward turn (white arrows) of the optimal values for all three parameters, occurring at an RV AV delay just shy of their respective intrinsic $P Q$ duration.

Several parameters have been used to judge which AV and VV delays result in the best CRT response. These include diastolic filling time, aortic velocity time integral, arterial blood pressure, LV $\mathrm{dP} / \mathrm{dt}_{\max }, \mathrm{SW}$, and vectorcardiography. ${ }^{46,47}$ However, a major problem seems to be that the increase in pump function is in the same order of magnitude as the biologic variability. According to basic rules for accurate measurements, reliable results are only observed if repeated measurements are performed. ${ }^{48}$ That this has rarely been done may explain the variable results on the best way and clinical effect of $\mathrm{AV}$ and $\mathrm{VV}$ optimization. A possible solution to this problem is the
A

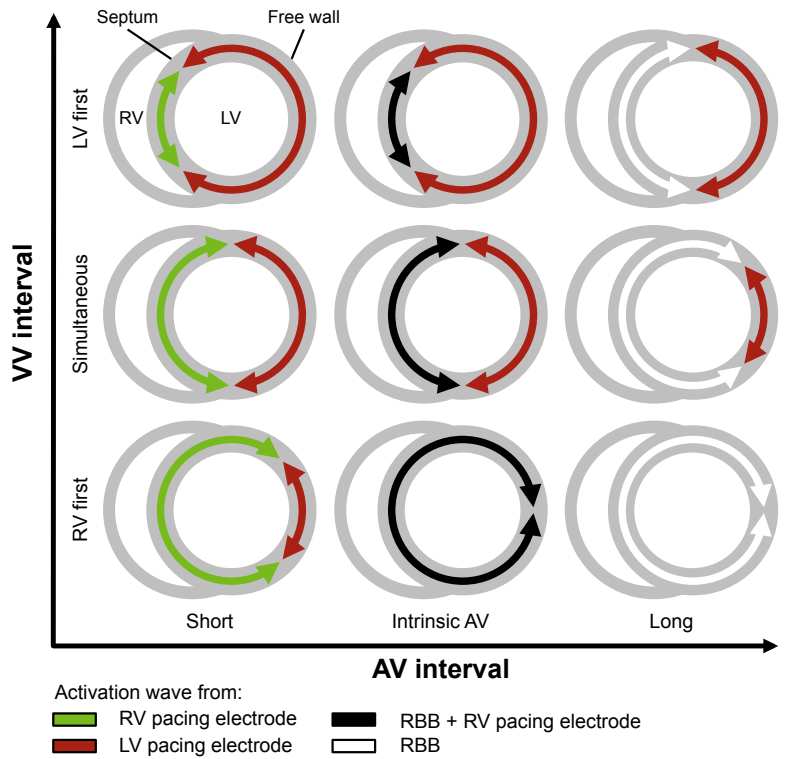

B

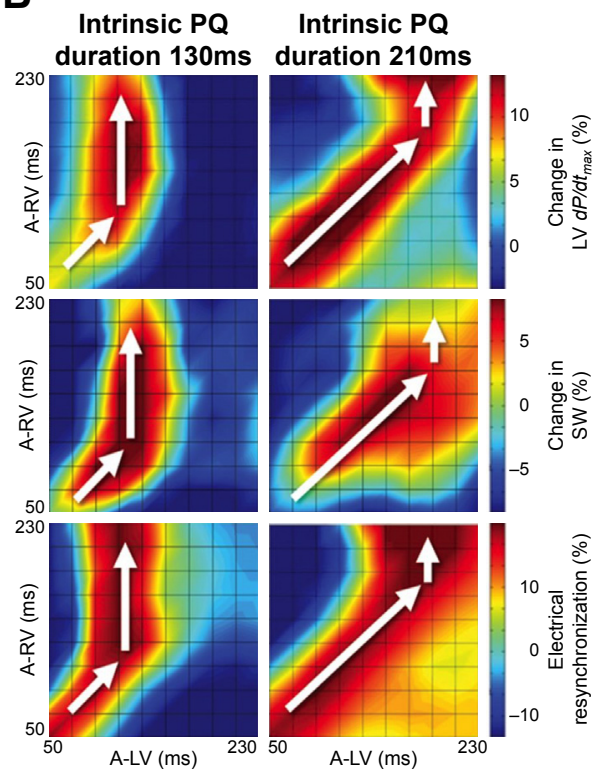

Fig. 6. Changes in resynchronization and pump function after biventricular CRT. $(A)$ Schematic representation of interactions between activation wavefronts originating from the RV and LV pacing electrodes and from the right bundle branch (RBB). (B) Contour plots of percentage change in LV dP/dtmax (maximal rate of rise of left ventricular pressure; top), stroke work (SW) (middle), and electric resynchronization (bottom) in 100 different combinations of atrio-left ventricular (A-LV) and atrio-right ventricular (A-RV) intervals in two different experiments with an intrinsic PQ duration of 130 (left) and 210 ms (right). (Adapted from Strik M, van Middendorp LB, Houthuizen $P$, et al. Interplay of electrical wavefronts as determinant of the response to cardiac resynchronization therapy in dyssynchronous canine hearts. Circ Arrhythm Electrophysiol 2013;6(5):928; with permission.) 
use of ECG or vectorcardiogram variables for optimization, which are both easy to acquire and have considerably lower variability. ${ }^{49}$

\section{SUMMARY}

CRT successfully improves cardiac function in HF patients with LBBB by resynchronizing the dyssynchronous contraction of the LV. Studies in patients and animals have indicated that the best electromechanical improvement is achieved by selecting the proper site for LV lead placement and by avoiding areas with transmural scarring. The acute effects of multiple pacing locations, endocardial pacing, and optimized timing of pacing are superior to conventional CRT, but further research on the long-term effects of these promising approaches is still needed.

\section{REFERENCES}

1. Verbeek XA, Vernooy K, Peschar M, et al. Quantification of interventricular asynchrony during LBBB and ventricular pacing. Am J Physiol Heart Circ Physiol 2002;283(4):H1370-8.

2. Houthuizen P, Van Garsse LA, Poels TT, et al. Left bundle-branch block induced by transcatheter aortic valve implantation increases risk of death. Circulation 2012;126(6):720-8.

3. Leclercq C, Kass DA. Retiming the failing heart: principles and current clinical status of cardiac resynchronization. J Am Coll Cardiol 2002;39(2):194-201.

4. Verbeek XA, Vernooy K, Peschar M, et al. Intra-ventricular resynchronization for optimal left ventricular function during pacing in experimental left bundle branch block. J Am Coll Cardiol 2003;42(3):558-67.

5. Daubert JC, Ritter P, Le Breton H, et al. Permanent left ventricular pacing with transvenous leads inserted into the coronary veins. Pacing Clin Electrophysiol 1998;21(1 Pt 2):239-45.

6. Leclercq C, Cazeau S, Le Breton H, et al. Acute hemodynamic effects of biventricular DDD pacing in patients with end-stage heart failure. J Am Coll Cardiol 1998;32(7):1825-31.

7. Kass DA, Chen $\mathrm{CH}$, Curry $\mathrm{C}$, et al. Improved left ventricular mechanics from acute VDD pacing in patients with dilated cardiomyopathy and ventricular conduction delay. Circulation 1999;99(12): 1567-73.

8. Brignole M, Auricchio A, Baron-Esquivias G, et al. 2013 ESC guidelines on cardiac pacing and cardiac resynchronization therapy: the task force on cardiac pacing and resynchronization therapy of the European Society of Cardiology (ESC). Developed in collaboration with the European Heart Rhythm Association (EHRA). Europace 2013; 15(8):1070-118.
9. Abraham WT, Fisher WG, Smith AL, et al. Cardiac resynchronization in chronic heart failure. N Engl J Med 2002;346(24):1845-53.

10. Strik M, van Middendorp LB, Vernooy K. Animal models of dyssynchrony. J Cardiovasc Transl Res 2012;5(2):135-45.

11. Liu L, Tockman B, Girouard S, et al. Left ventricular resynchronization therapy in a canine model of left bundle branch block. Am J Physiol Heart Circ Physiol 2002;282(6):H2238-44.

12. Vernooy K, Cornelussen RN, Verbeek XA, et al. Cardiac resynchronization therapy cures dyssynchronopathy in canine left bundle-branch block hearts. Eur Heart J 2007;28(17):2148-55.

13. Auricchio A, Fantoni C, Regoli F, et al. Characterization of left ventricular activation in patients with heart failure and left bundle-branch block. Circulation 2004;109(9):1133-9.

14. Lambiase PD, Rinaldi A, Hauck J, et al. Non-contact left ventricular endocardial mapping in cardiac resynchronisation therapy. Heart 2004;90(1):44-51.

15. Strik M, Regoli F, Auricchio A, et al. Electrical and mechanical ventricular activation during left bundle branch block and resynchronization. J Cardiovasc Transl Res 2012;5(2):117-26.

16. Strik M, van Deursen CJ, van Middendorp LB, et al. Transseptal conduction as an important determinant for cardiac resynchronization therapy, as revealed by extensive electrical mapping in the dyssynchronous canine heart. Circ Arrhythm Electrophysiol 2013;6(4):682-9.

17. Helm PA, Younes L, Beg MF, et al. Evidence of structural remodeling in the dyssynchronous failing heart. Circ Res 2006;98(1):125-32.

18. Ghosh S, Silva JN, Canham RM, et al. Electrophysiologic substrate and intraventricular left ventricular dyssynchrony in nonischemic heart failure patients undergoing cardiac resynchronization therapy. Heart Rhythm 2011;8(5):692-9.

19. Russell K, Eriksen M, Aaberge L, et al. Assessment of wasted myocardial work: a novel method to quantify energy loss due to uncoordinated left ventricular contractions. Am J Physiol Heart Circ Physiol 2013; 305(7):H996-1003.

20. Leyva F, Nisam S, Auricchio A. 20 years of cardiac resynchronization therapy. J Am Coll Cardiol 2014; 64(10): 1047-58.

21. Auricchio A, Stellbrink C, Block M, et al. Effect of pacing chamber and atrioventricular delay on acute systolic function of paced patients with congestive heart failure. The Pacing Therapies for Congestive Heart Failure Study Group. The Guidant Congestive Heart Failure Research Group. Circulation 1999; 99(23):2993-3001.

22. Gold MR, Auricchio A, Hummel JD, et al. Comparison of stimulation sites within left ventricular veins on the acute hemodynamic effects of cardiac 
resynchronization therapy. Heart Rhythm 2005;2(4): 376-81.

23. de Roest GJ, Allaart CP, Kleijn SA, et al. Prediction of long-term outcome of cardiac resynchronization therapy by acute pressure-volume loop measurements. Eur J Heart Fail 2013;15(3):299-307.

24. Bogaard MD, Houthuizen P, Bracke FA, et al. Baseline left ventricular $\mathrm{dP} / \mathrm{dtmax}$ rather than the acute improvement in $\mathrm{dP} / \mathrm{dtmax}$ predicts clinical outcome in patients with cardiac resynchronization therapy. Eur J Heart Fail 2011;13(10):1126-32.

25. Steendijk P, Tulner SA, Bax JJ, et al. Hemodynamic effects of long-term cardiac resynchronization therapy: analysis by pressure-volume loops. Circulation 2006;113(10):1295-304.

26. Yu CM, Chau E, Sanderson JE, et al. Tissue Doppler echocardiographic evidence of reverse remodeling and improved synchronicity by simultaneously delaying regional contraction after biventricular pacing therapy in heart failure. Circulation 2002;105(4): 438-45.

27. Vernooy K, van Deursen CJ, Strik M, et al. Strategies to improve cardiac resynchronization therapy. Nat Rev Cardiol 2014;11(8):481-93.

28. Helm RH, Byrne M, Helm PA, et al. Three-dimensional mapping of optimal left ventricular pacing site for cardiac resynchronization. Circulation 2007; 115(8):953-61.

29. Rad MM, Blaauw Y, Dinh T, et al. Left ventricular lead placement in the latest activated region guided by coronary venous electroanatomic mapping. Europace 2015;17(1):84-93.

30. Khan FZ, Virdee MS, Palmer CR, et al. Targeted left ventricular lead placement to guide cardiac resynchronization therapy: the TARGET study: a randomized, controlled trial. J Am Coll Cardiol 2012; 59(17):1509-18.

31. Mafi Rad M, Blaauw Y, Dinh T, et al. Different regions of latest electrical activation during left bundlebranch block and right ventricular pacing in cardiac resynchronization therapy patients determined by coronary venous electro-anatomic mapping. Eur J Heart Fail 2014;16(11):1214-22.

32. Ludwig DR, Tanaka H, Friehling M, et al. Further deterioration of LV ejection fraction and mechanical synchrony during RV apical pacing in patients with heart failure and LBBB. J Cardiovasc Transl Res 2013:6(3):425-9.

33. Ypenburg C, Schalij MJ, Bleeker GB, et al. Impact of viability and scar tissue on response to cardiac resynchronization therapy in ischaemic heart failure patients. Eur Heart J 2007;28(1):33-41.

34. Bleeker GB, Kaandorp TA, Lamb HJ, et al. Effect of posterolateral scar tissue on clinical and echocardiographic improvement after cardiac resynchronization therapy. Circulation 2006; 113(7):969-76.
35. Rademakers LM, van Kerckhoven $R$, van Deursen CJ, et al. Myocardial infarction does not preclude electrical and hemodynamic benefits of cardiac resynchronization therapy in dyssynchronous canine hearts. Circ Arrhythm Electrophysiol 2010;3(4):361-8.

36. Leclercq C, Gadler F, Kranig W, et al. A randomized comparison of triple-site versus dual-site ventricular stimulation in patients with congestive heart failure. J Am Coll Cardiol 2008;51(15):1455-62.

37. Ploux S, Strik M, van Hunnik A, et al. Acute electrical and hemodynamic effects of multisite left ventricular pacing for cardiac resynchronization therapy in the dyssynchronous canine heart. Heart Rhythm 2014; 11(1):119-25.

38. Pappone C, Calovic Z, Vicedomini G, et al. Multipoint left ventricular pacing improves acute hemodynamic response assessed with pressure-volume loops in cardiac resynchronization therapy patients. Heart Rhythm 2014;11(3):394-401.

39. Shetty AK, Sohal M, Chen Z, et al. A comparison of left ventricular endocardial, multisite, and multipolar epicardial cardiac resynchronization: an acute haemodynamic and electroanatomical study. Europace 2014;16(6):873-9.

40. van Deursen C, van Geldorp IE, Rademakers LM, et al. Left ventricular endocardial pacing improves resynchronization therapy in canine left bundlebranch hearts. Circ Arrhythm Electrophysiol 2009; 2(5):580-7.

41. Garrigue S, Jais P, Espil G, et al. Comparison of chronic biventricular pacing between epicardial and endocardial left ventricular stimulation using Doppler tissue imaging in patients with heart failure. Am J Cardiol 2001;88(8):858-62.

42. Bordachar P, Grenz N, Jais P, et al. Left ventricular endocardial or triventricular pacing to optimize cardiac resynchronization therapy in a chronic canine model of ischemic heart failure. Am J Physiol Heart Circ Physiol 2012;303(2):H207-15.

43. Strik M, Rademakers LM, van Deursen CJ, et al. Endocardial left ventricular pacing improves cardiac resynchronization therapy in chronic asynchronous infarction and heart failure models. Circ Arrhythm Electrophysiol 2012;5(1):191-200.

44. Rademakers LM, van Gelder BM, Scheffer MG, et al. Mid-term follow up of thromboembolic complications in left ventricular endocardial cardiac resynchronization therapy. Heart Rhythm 2014;11(4): 609-13.

45. Strik M, van Middendorp LB, Houthuizen P, et al. Interplay of electrical wavefronts as determinant of the response to cardiac resynchronization therapy in dyssynchronous canine hearts. Circ Arrhythm Electrophysiol 2013;6(5):924-31.

46. International Working Group on Quantitative Optimization, Sohaib SM, Whinnett ZI, et al. Cardiac 
resynchronisation therapy optimisation strategies: systematic classification, detailed analysis, minimum standards and a roadmap for development and testing. Int J Cardiol 2013;170(2):118-31.

47. van Deursen CJ, Strik M, Rademakers LM, et al. Vectorcardiography as a tool for easy optimization of cardiac resynchronization therapy in canine left bundle branch block hearts. Circ Arrhythm Electrophysiol 2012;5(3):544-52.
48. Whinnett ZI, Francis DP, Denis A, et al. Comparison of different invasive hemodynamic methods for AV delay optimization in patients with cardiac resynchronization therapy: implications for clinical trial design and clinical practice. Int J Cardiol 2013;168(3):2228-37.

49. van Deursen CJ, Wecke L, van Everdingen WM, et al. Vectorcardiography for optimization of stimulation intervals in cardiac resynchronization therapy. J Cardiovasc Transl Res 2015;8(2):128-37. 